Document downloaded from:

http://hdl.handle.net/10251/102343

This paper must be cited as:

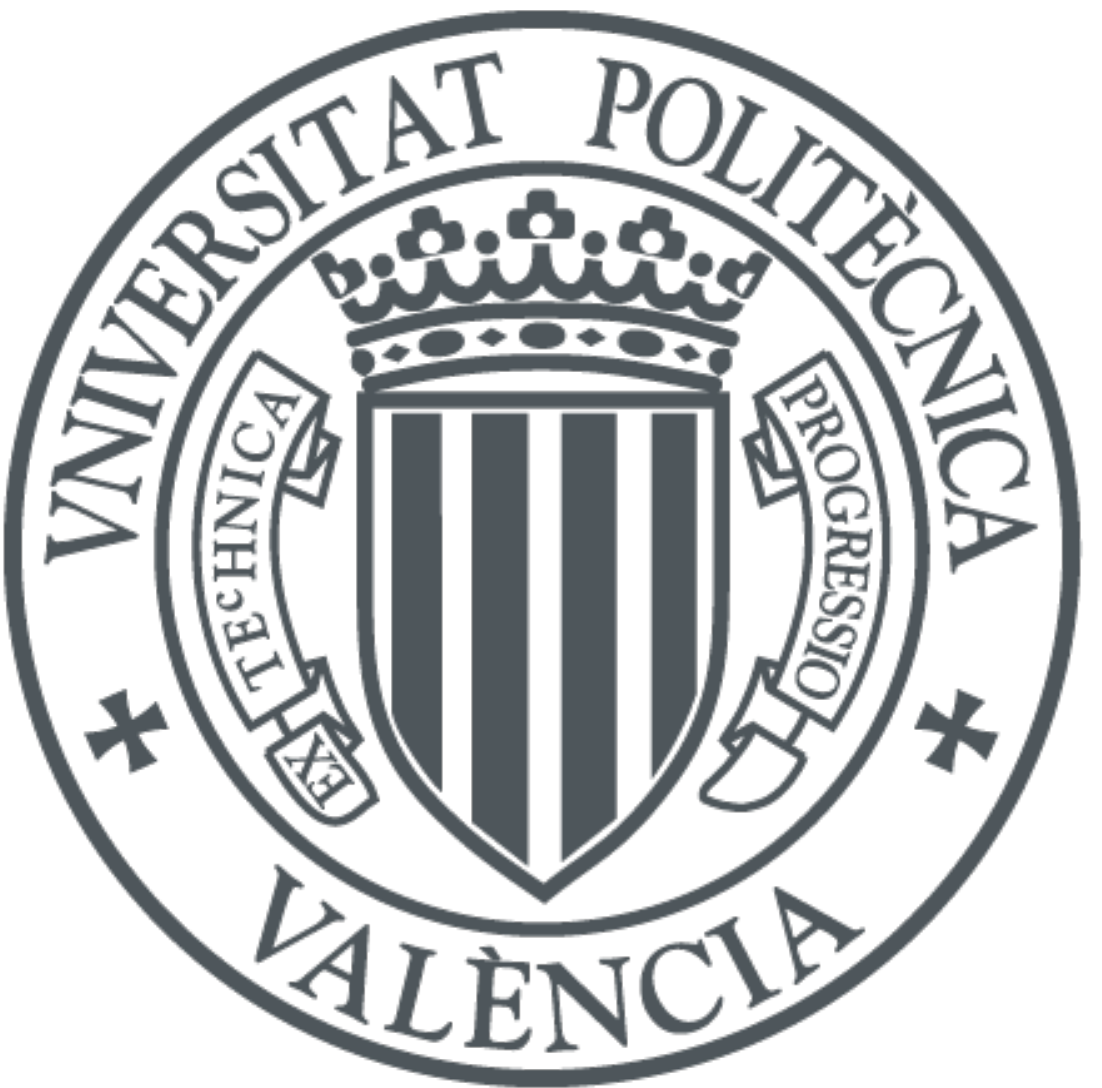

The final publication is available at

https://doi.org/10.1007/s40799-016-0154-1

Copyright Springer-Verlag

Additional Information 


\title{
Methodology for phase doppler anemometry measurements on a multi-hole diesel injector
}

\author{
Raul Payri*, Jaime Gimeno, Pedro Martí-Aldaraví, Jhoan S. Giraldo \\ CMT - Motores Térmicos, Universidad Politécnica de Valencia, Edificio 6D, 46022, Valencia, Spain
}

\begin{abstract}
In this paper, a methodology for Phase Doppler Anemometry (PDPA) measurements on a multi-hole diesel injector is developed. Several key considerations were taken into account in this methodology: The windows for PDPA optical access must be clean, since fuel impregnated in these could preclude the droplets velocity acquisition. Some parts, including a device for spray isolation, were designed and manufactured to fulfill this goal. Taking into account that only one spray is measured, the isolation device captures all except three of the sprays (including the spray of interest). The two plumes accompanying the main spray were thought to conserve the actual air entrainment and thus the spray behavior. The spray of interest was aligned horizontally to ease the way that the PDPA measurements are carried out. The plume was lined up by means of the MIE-Scattering macroscopic optical technique. Images were acquired for several injection events and spray contours were detected and processed with a purpose-built Matlab tool. At each time step a spray axis inclination was estimated using the centroids from instantaneous contours. Also, preliminary droplet velocity measurements were made to check the effectiveness of the alignment and spray isolation strategies. Both geometrical characterization and spray alignment had very low measurement error. Radial velocity profiles show that PDPA measurements with this set-up configuration preserved the spray behavior.
\end{abstract}

Keywords:

Phase doppler anemometry, Diesel sprays, Spray isolation, Multi-hole injector, MIE-Scattering

* Corresponding author. Tel.: +34 963877650; fax: +34 963877659. E-mail addresses: rpayri@mot.upv.es (Raúl Payri), jaigigar@mot.upv.es (Jaime Gimeno), pedmar15@mot.upv.es (Pedro Martí-Aldaraví), jghi@mot.upv.es (Jhoan S. Giraldo). 
Raúl Payri, J. Gimeno, P. Martí-Aldaraví, Jhoan S. Giraldo; Methodology for Phase Doppler Anemometry Measurements on a Multi-Hole Diesel Injector. Experimental Techniques, 2016, 26, 889-919.

\section{Introduction}

2 In the quest of improving the diesel engine performance and efficiency it is clear that 3 a great effort should be focus on the injection process. These improvements can only 4 be made if there is a fully and detailed understanding of all the processes implicated 5 with the fuel mixture, evaporation and the subsequent combustion process. Multi-hole injectors have been employed in the present days in order to achieve a more homogeneous mixture and to decrease the droplet size and thus increase the liquid-gas contact surface [1. For this reason, the use of multi-hole diesel injectors offers many advantages including a significant optimization of the combustion behavior and soot emissions [2]. Despite all these benefits, the spray atomization process behavior is not clearly identified for multihole injectors [3], accordingly, the characterization of these injectors is still a topic of interest in the engine community 2, 4, 5, . There are several parameters that help to characterize the diesel spray from a macroscopic point of view. The liquid length is an indicator of the evaporation of the fuel and it is defined as the distance from the nozzle orifice to the point where droplets are fully vaporized. MIE-Scattering imaging technique is widely used by the engine community for the visualization of the fuel spray liquid phase. This technique consists in illuminating the fuel droplets with a light source and collecting the light scattered with a camera [6] 8].

From a microscopic point a view, some techniques quantify spray parameters like droplets size and velocities. Phase Doppler Anemometry (PDPA) is usually used to measure these parameters, its non-intrusive droplet diameter and velocity measurements in multi-phase flows make this technique interesting for diesel spray characterization [9 11]. This system emits one beam which is splitted in two components of equal intensity but with different phase, these beams are then intersected creating a probe volume where the measures will be made, the intersection of these beams form a fringe pattern. When a particle traverses the control volume, the amount of light received fluctuates with the fringes and this is then collected by another lens and focused onto a photo-detector which converts the fluctuations of light intensity into fluctuations of a voltage signal. The frequency of this fluctuation is proportional to the velocity of the particle and the spatial frequency is inversely proportional to the droplet diameter [12].

The application of this technique to diesel sprays is not a new idea, however it has always been a complicated problem due the extreme droplet concentration typical for these sprays and to a lesser degree to their high droplet velocities. The high density of the diesel spray is a physical limitation for the PDPA technique that can only be overcome if the measurement volume is small enough to allow a single droplet passing through it at the time [9-11].

There are two things that have to be considered when a multi-hole diesel injector is analyzed with a PDPA system. First, operating conditions must be established in order to obtain reliable results congruent with the physics of the spray at actual engine conditions. It is generally accepted that the behavior of the spray mainly depends on ambient density, not on ambient pressure [13, 14]. For this reason a test rig able to achieve engine chamber 
Raúl Payri, J. Gimeno, P. Martí-Aldaraví, Jhoan S. Giraldo; Methodology for Phase Doppler Anemometry Measurements on a Multi-Hole Diesel Injector. Experimental Techniques, 2016, 26, 889-919.

densities is enough to carry out this kind of study.

Second, to have the proper optical access in the test rig is essential. In this manner, laser beams from the PDPA system are allowed to get into the chamber and create a control volume in the spray that will be measured.

In this paper a methodology for PDPA measurements on a multi-hole diesel injector is presented. Since only one of the sprays was planned to be measured, a device for spray isolation has been designed. A preliminary lined up of the spray of interest was made by means of the MIE-Scattering optical technique. The image processing has been performed through a purpose-built Matlab code. Preliminary measurements are shown as well. The methodology presented here can be applied to any PDPA measurement for a multi-hole diesel injector.

\section{Experimental facilities}

\subsection{High density test rig and optical set-up}

The main facility used in this work consists of an purpose-built test rig manufactured mainly in steel and used in a previous work [7], featuring an optical access which allows the laser beams from PDPA system to get into the chamber. The test rig offers better optical access than a normal engine but can still reproduce the ambient density from the combustion chamber at the moment of injection. As the behavior of non-evaporative sprays manly depends on chamber density [13, 14], ambient conditions are achieved with a gas with high molecular mass (Sulphur hexafluoride-SF6) and varying ambient pressure. Due to its high molecular mass, this gas can reach the density values that normally occur in a diesel engine at the moment of the injection $\left(10\right.$ to $\left.40 \mathrm{~kg} / \mathrm{m}^{3}\right)$ at much lower ambient pressures $(0.2$ to $0.5 \mathrm{MPa})$. Temperature was kept constant at $25^{\circ} \mathrm{C}$.

The gas is continuously circulated, passing through filters that remove the injected fuel and then through the roots compressor that sends it back to the testing section. The flow velocity next to the injector is lower than $2 \mathrm{~m} / \mathrm{s}$ [7], so that it does not affect the diesel spray.

For the injector alignment procedure that will be described in detail in following sections, the spray was illuminated by a light source. A fast camera imaged the scattered light from the fuel droplets. Images were taken with a high speed CMOS camera Phantom V12, equipped with a $100 \mathrm{~mm}$ focal length ZEISS lens, an image resolution of $680 \mathrm{x}$ 304 pixels was used. The illumination used was a continuous light source provided by a $150 \mathrm{~W}$ quartz-halogen illuminator (Dolan-Jenner PL800), supplied by $8 \mathrm{~mm}$ optic fiber bundles positioned at $\sim 200 \mathrm{~mm}$ from the spray, sharply collimated and focused on the studied area. Each picture pixel corresponds to $3.1 \mathrm{~mm}$. A picture of the test rig and MIE-Scattering set-up is shown in fig. 1 . 


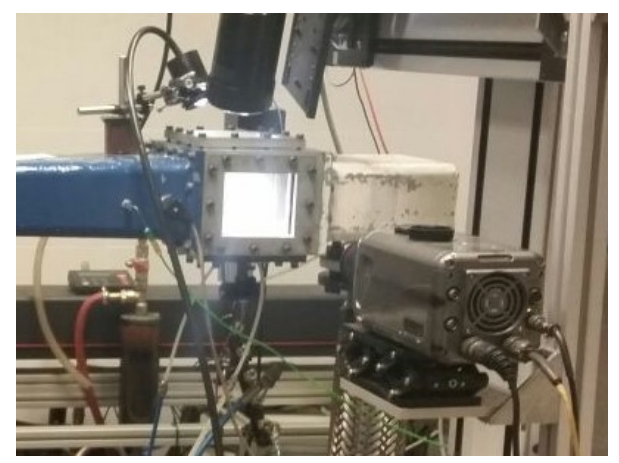

Figure 1: MIE Scattering configuration and test rig

\subsection{Fuel injection system}

The feeding system of fuel consists in a high pressure volumetric pump driven by an electric motor and a common-rail with pressure regulator controlled by a PID system. This system allows injections at high pressures up to $270 \mathrm{MPa}$. The injector employed is a 8-nozzle Bosch second generation solenoid type, with a nominal nozzle outlet diameter of $135 \mu \mathrm{m}$.

Moreover, a special injector holder has been designed specifically for this work: this device maintains the injector in direct contact with a liquid flowing at controlled temperature. The liquid temperature is controlled by means of a PID system able to feed the liquid at temperatures ranging from 15 to $90{ }^{\circ} \mathrm{C}$. This temperature was kept constant at $60{ }^{\circ} \mathrm{C}$ for all measurements.

\subsection{PDPA system and assembly of the injector with the test rig}

The first step to assemble the diesel injector with the test rig was to carry out a geometrical characterization. The diesel injector used in this work has an angle among all sprays $(\beta)$ of $153.9^{\circ}$ (fig. $2 \mathrm{~b}$ ), this opening angle was obtained injecting diesel at 900 bar over several paper sheets as shown in fig. 2a. These injections were made at atmospheric conditions, accordingly, sprays have a needle like shape provoked by the low transfer of momentum between the spray and the atmosphere. The sprays perforate the paper sheet. With the axial and radial distance between these holes and the nozzle tip position the angle among sprays can be estimated by applying simple trigonometry. This strategy was repeated with five paper sheets, consequently, the obtained angles were averaged. The standard deviation of this angle calculation was $0.43^{\circ}$. 
Raúl Payri, J. Gimeno, P. Martí-Aldaraví, Jhoan S. Giraldo; Methodology for Phase Doppler Anemometry Measurements on a Multi-Hole Diesel Injector. Experimental Techniques, 2016, 26, 889-919.

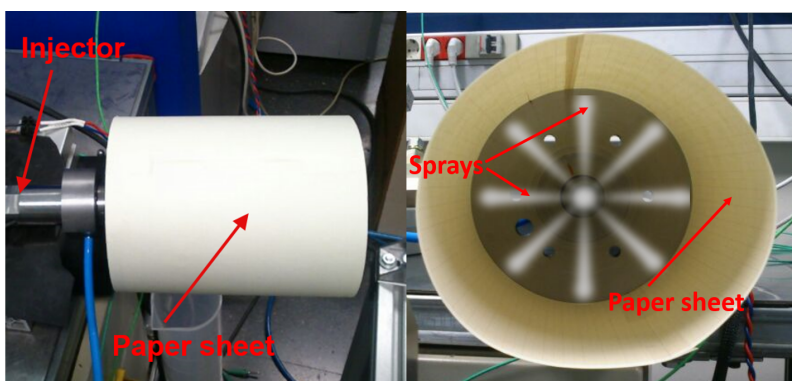

(a)

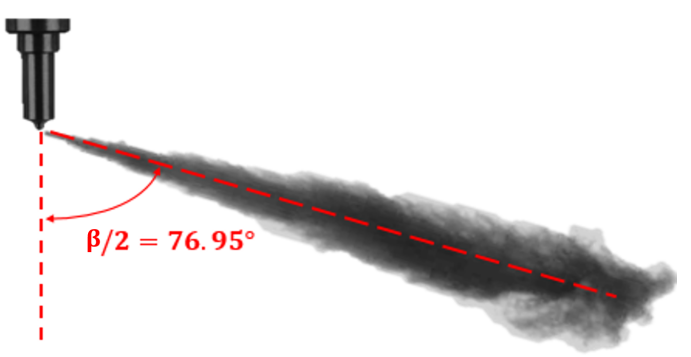

(b)

Figure 2: Strategy for opening angle estimation (a) Technique description (b) Opening angle.

The instrument used in this work is a PDPA system with an FSA4000 digital processor manufactured by TSI Inc. Its main parameters were studied in a previous work [12]. In that study the angle between emitter and the receiver from the PDPA system was optimized and then settled in $110^{\circ}$ (fig. 3a). The experimental set-up was adapted to satisfy this requirement.

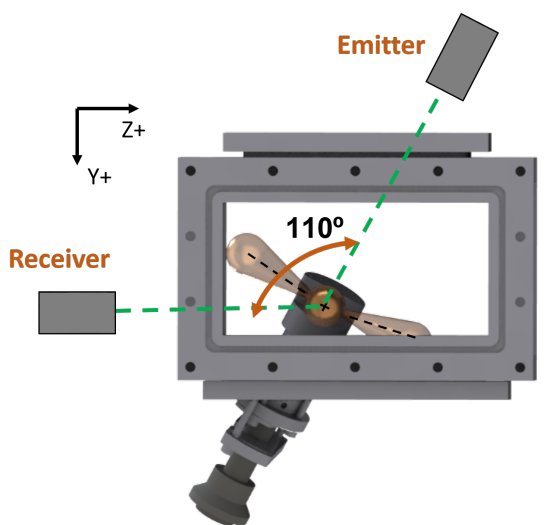

(a)

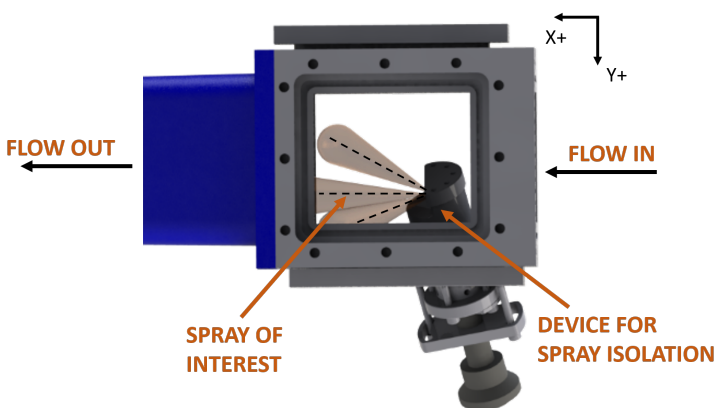

(b)

Figure 3: Multi-hole diesel injector assembled in the test rig be measured, some parts were designed and manufactured in order to adapt its geometry with the test rig and based on the following requirements: the injector has 8 orifices, however only one of these sprays will be analyzed (any of these sprays can be selected for measurements). The probe volume generated by the PDPA system must be able to be located at any section across the spray of interest to acquire data of droplet velocities and diameters in these locations. Windows must be clean during PDPA measurements. Also, the spray to be measured was thought to come out from the nozzle horizontally $3 \mathrm{~b}$ to ease the way that the probe volume is located across the spray.

The soiling of the test rig windows with diesel is a big problem in PDPA measurements for multi-hole injectors, as the sprays are usually directed towards them. These windows 
provide the optical access needed for the laser beams, to get into the chamber and create the probe volume. Impregnated diesel in the windows could preclude the measurements. For this reason it was also thought to obstruct all the orifices of the injector except for three of them, in order to avoid sudden changes in the structure of the spray of interest. But considering that the obstruction of some holes changes the internal nozzle flow and thereby the spray structure [15], it was decided to collect them instead. Hence, a device for isolate sprays was designed, to collect mainly those who have no direct effect on the spray of interest (figs. $4 \mathrm{a}$ to $4 \mathrm{c}$ ). The device was dimensioned taking into account the number of orifices that the injector had. In fig. $4 \mathrm{c}$ the device dimensions for the injector used in this work can be observed. The sprays are collected in a small chamber where the residual diesel is evacuated through several holes in the top cover of the device.

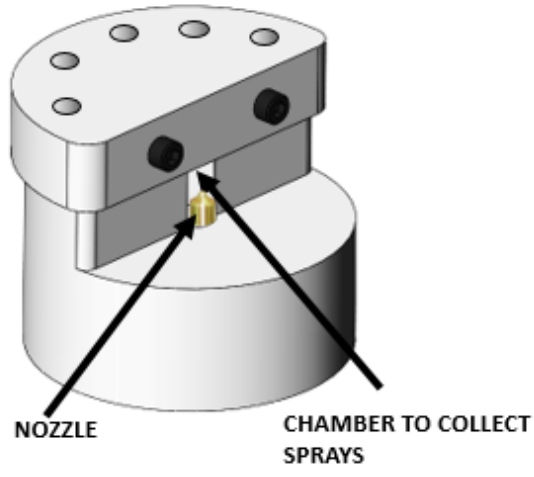

(a)

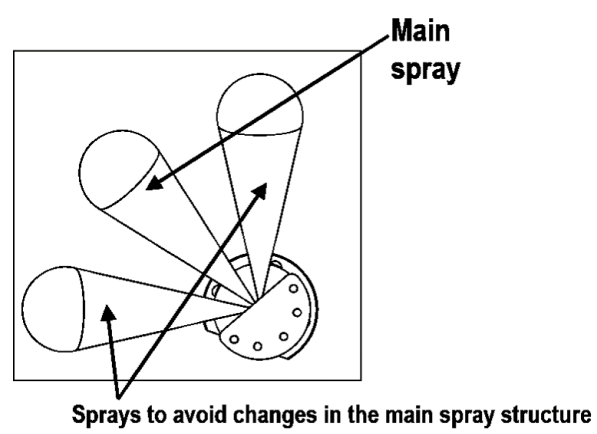

(b)

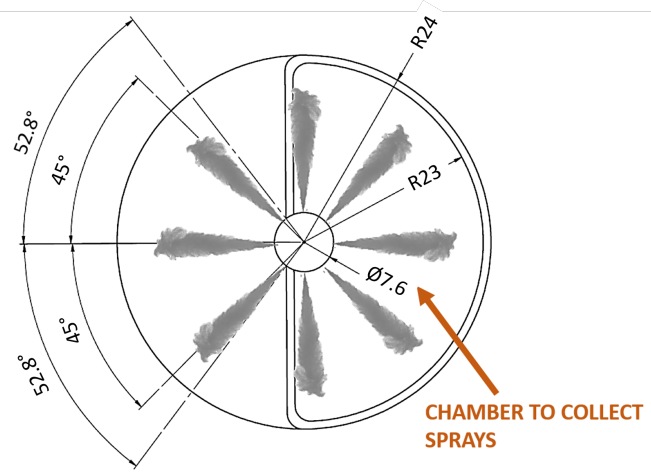

(c)

Figure 4: Device for spray isolation (a) Device 3d view (b) Upper view with sprays (c) Upper view without the top cover.

PDPA laser beams enter into the test rig through the top window of the test rig generating the control volume probe, the photo-detector receiver captures light frequency of the droplets passing through the probe. Therefore, both the top and lateral (in front of the receiver) windows shall be kept clean. The bottom cover of the test rig, where the injector is placed, has been designed so that the sprays will not impinge the most crucial 
Raúl Payri, J. Gimeno, P. Martí-Aldaraví, Jhoan S. Giraldo; Methodology for Phase Doppler Anemometry Measurements on a Multi-Hole Diesel Injector. Experimental Techniques, 2016, 26, 889-919.

windows for these measurements (figs. 5a to 5c). In fig. 5a, the bottom cover is shown assembled with the diesel injector, it can be seen that the sprays are far enough from the lateral window near the receiver. The injector is also connected with a holder (fig. 5d) provided with several internal ducts used to keep the temperature of the injector constant during the measurements.

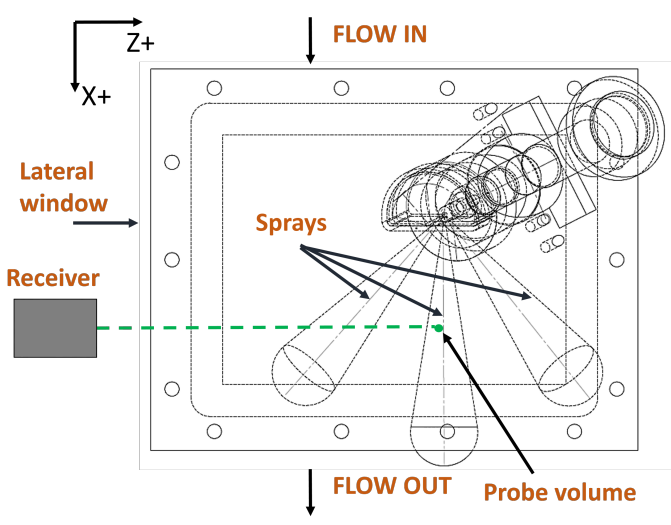

(a)

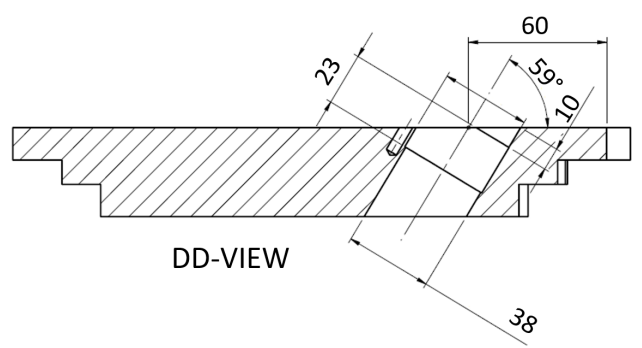

(c)

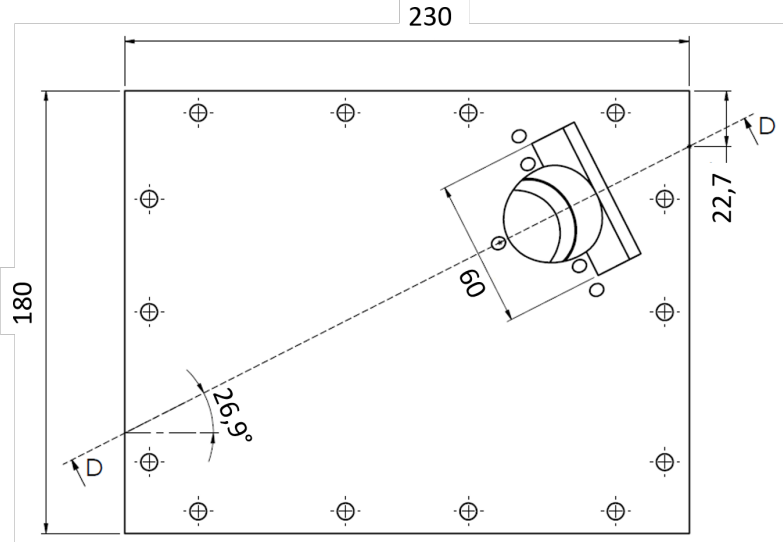

(b)

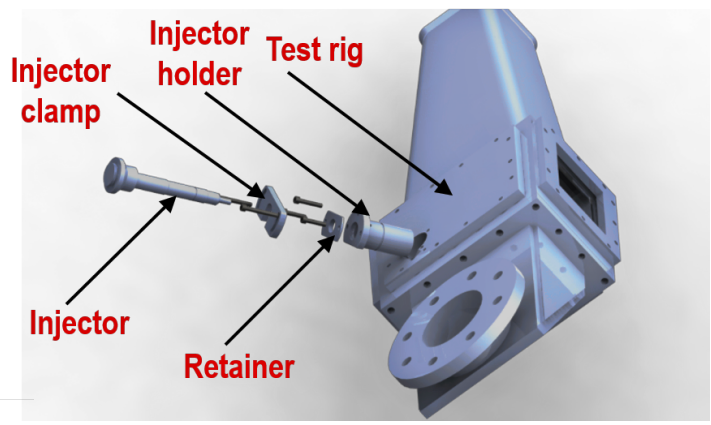

(d)

Figure 5: Designed bottom cover of the test rig. (a) Bottom cover of the test rig assembled with the injector (b) Bottom cover dimensions (c) Bottom cover dimensions, D-D View (d) Test rig assemble with the injector.

\section{Methodology for spray of interest alignment}

The alignment of the spray of interest was made by means of MIE-Scattering visualization. The main idea was to find the spray axis by detecting the spray contour. For contour detection, an image segmentation was done first [16]. A fixed threshold method has been used, which corresponds to $3 \%$ of the maximum digital level obtained in the core of the spray. Then this threshold is employed for image binarization after a background arithmetical subtraction. This method is extensively used in MIE-Scattering imaging since it scales the sensitivity to the illumination intensity [7, 16, 17] . 
With the PDPA system off, 10 injections were recorded using 18000 fps and an exposure time of $55 \mu \mathrm{s}$, for each injection event 60 images were acquired. For each time step a centroid was calculated using the contoured area of the spray (fig. 7b), the angle formed by the junction centroid-spray origin and a horizontal line at each time step can be estimated. In fig. 6, it can be seen these calculated angles for each injection event. Afterwards, centroid angles between $1 \mathrm{~ms}$ and $3 \mathrm{~ms}$ are averaged, since angle variations in this range are minimized. In this example the angle was $-0.13^{\circ}$ and the standard deviation was $0.22^{\circ}$.

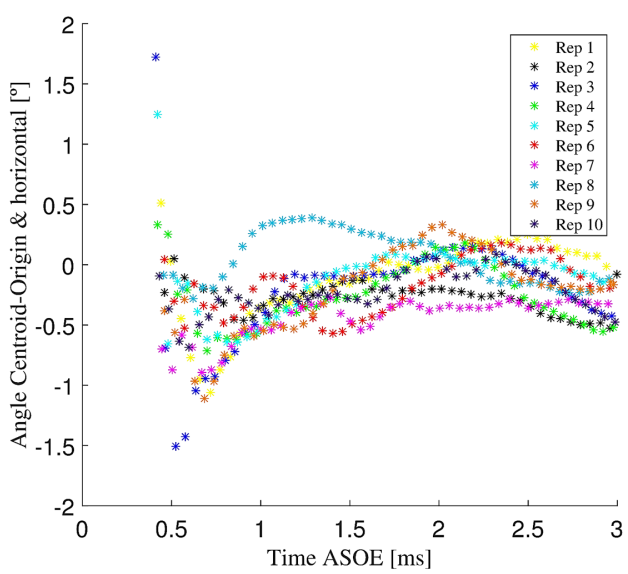

Figure 6: Centroid-Origin angle calculation for each repetition

In the test rig, the injector is then gently rotated until this inclination vanishes. Since PDPA measurements for velocities has been reported in some cases to be up to $5 \%$ [9], an uncertainty of $\pm 1^{\circ}$ has been defined as the acceptable to consider the spray "horizontal". After the alignment, the PDPA system is turned on. A single picture is taken at $1100 \mu \mathrm{s}$ after start of injection, using $4000 \mathrm{fps}$ and an exposure time of $400 \mu \mathrm{s}$ (fig. 7a), images at this high exposure time are more saturated and thereby the laser beams from PDPA can be clearly seen. In this image the probe volume created by the interference of the laser beams from the PDPA system can be located. The pixel $/ \mathrm{mm}$ and the image resolution was preserved for all measurements, consequently the perpendicular distance between the probe volume and the spray axis can be also known. From this point any position of the PDPA control volume can be referenced with the spray axis. 
Raúl Payri, J. Gimeno, P. Martí-Aldaraví, Jhoan S. Giraldo; Methodology for Phase Doppler Anemometry Measurements on a Multi-Hole Diesel Injector. Experimental Techniques, 2016, 26, 889-919.

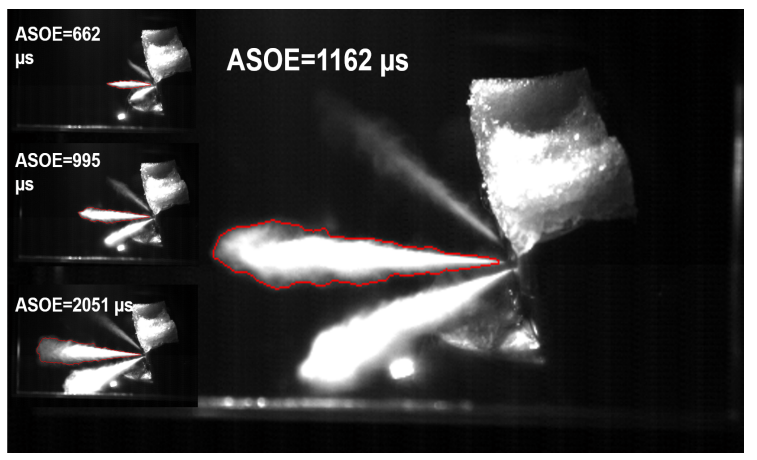

(a)

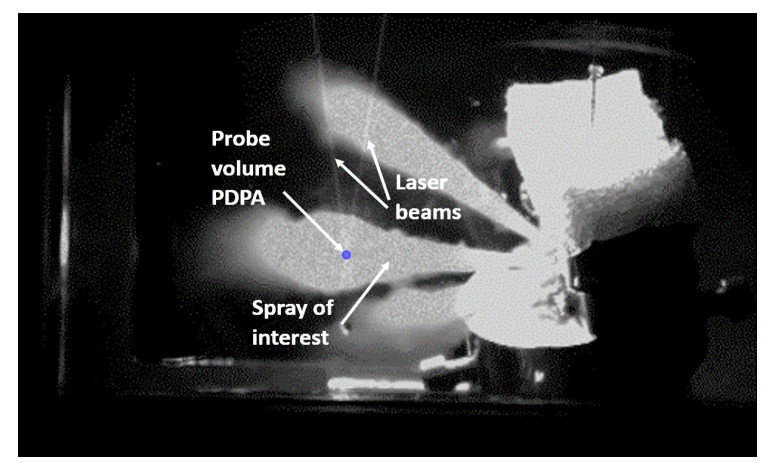

(b)

Figure 7: MIE- Scattering images acquired with the fast camera (a) Image at high exposure time of the spray and laser beams (b) Instantaneous contours used to calculate centroids.

\section{Preliminary measurements}

In order to confirm the effectiveness of the alignment methodology, some velocity measurements with the PDPA system has been carried out at several axial distances using an ambient density of $25 \mathrm{~kg} / \mathrm{m}^{3}$. The graph reported in fig. 8 shows the test plan used for the preliminary measurements. Due to the high droplets concentration common for these sprays, measurements at axial distances below $20 \mathrm{~mm}$ are almost impossible [18], therefore, three axial locations were studied (30, 40 and $50 \mathrm{~mm}$ from the nozzle tip), moving the measuring probe volume across the spray and along the radial direction at $-45^{\circ}$ in the Y-Z plane. The injection pressure was settled in 900 bar.

The cone angle of the spray $\theta_{u}$ was estimated with the spray contours obtained in the previous section. It was defined as the angle included between the two lines that fit the points on the spray contour in a specific region, and are forced to go through the outlet orifice. The region of the spray contour that is fitted goes from a $25 \%$ to $60 \%$ of the liquid spray penetration.
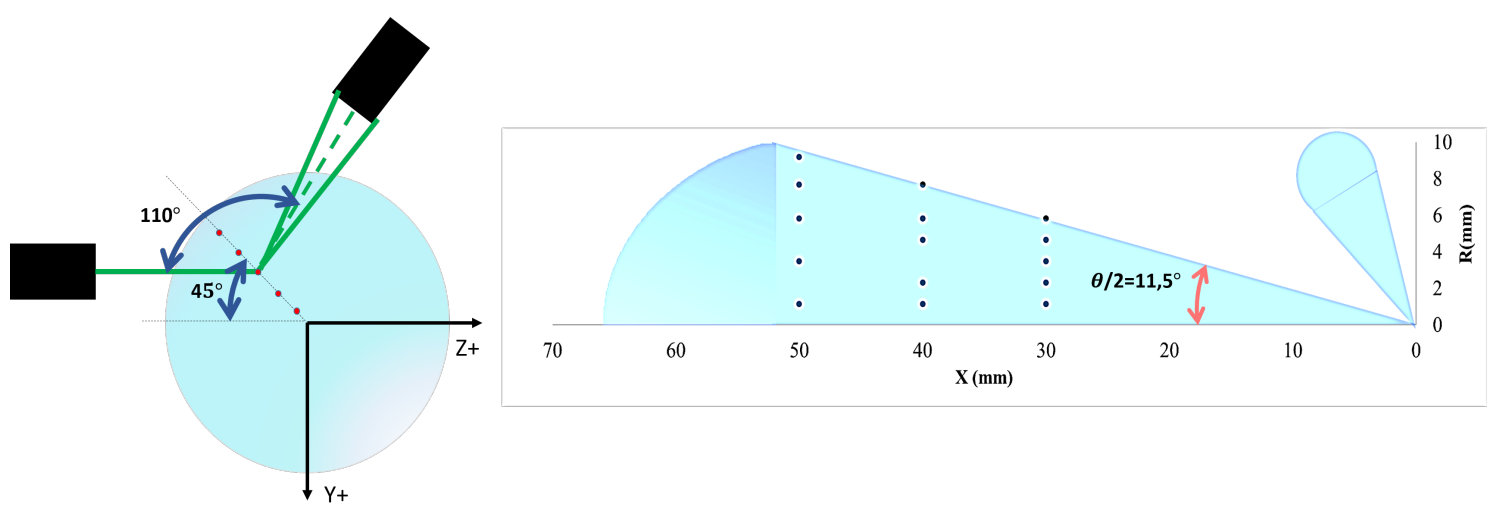

Figure 8: Test plan for preliminary measurements 
Raúl Payri, J. Gimeno, P. Martí-Aldaraví, Jhoan S. Giraldo; Methodology for Phase Doppler Anemometry Measurements on a Multi-Hole Diesel Injector. Experimental Techniques, 2016, 26, 889-919.

Fig. 9a shows a typical time-resolved evolution of the axial velocity and droplet diameter over time after start of energizing. The energizing time was set to $1.5 \mathrm{~ms}$. The evolution of each measurement can be divided in 4 phases: (1) The spray tip, (2) the quasi-stationary phase at the fully open nozzle, (3) quasi-stationary phase at the fully open nozzle with coalescence, (4) and the spray tail. A brief description of each of them is presented in [19]. The average velocity is obtained on data from the spray tip and both quasi-steady parts, therefore, only velocities within 1 and $3 \mathrm{~ms}$ are included in this average.

Radial velocity profiles were compared with a theoretical trend in order to check if the spray of interest was measured properly. Several equations that describe these profiles can be encountered in literature [20-23]. Desantes et al [21] emphasize that despite of all these profiles are very accurate, the following equation would be the best option in terms of MSD (Mean Squared Deviation):

$$
U(x, r)=U_{a x i s}(x) \exp \left(-\alpha\left(\frac{r}{R}\right)^{2}\right)
$$

Where $\mathrm{R}$ can be defined as:

$$
R=x \tan \left(\frac{\theta_{u}}{2}\right)
$$

Desantes et al. 24] have estimated that $\alpha$ value is equal to 4.6. Fig. 9b shows the axial mean velocity profiles, $U / U_{\text {axis }}$, normalized with the axial velocity of the spray centerline. The dotted line is the theoretical radial velocity profile obtained with 900 bar, an ambient density of $25 \mathrm{~kg} / \mathrm{m}^{3}$ and a spray angle $\theta_{u}$ of $23^{\circ}$.

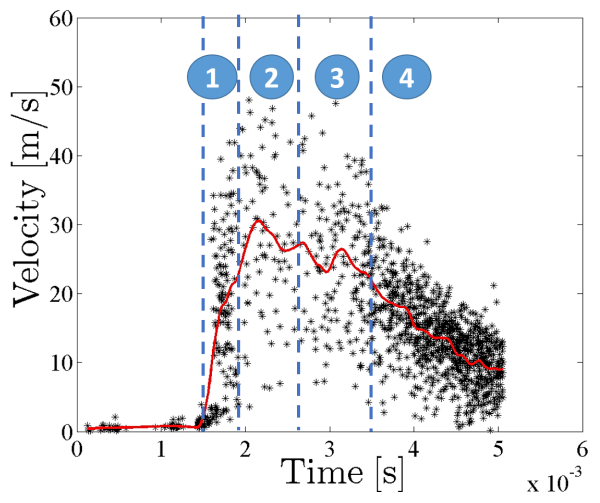

(a)

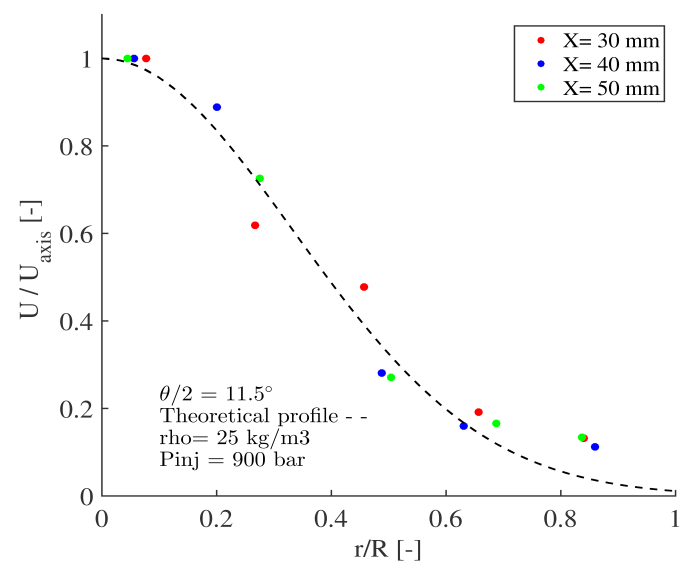

(b)

Figure 9: Preliminary measurements. (a) Time-resolved evolution of the axial velocity (b) Axial mean radial velocity profiles. 
Raúl Payri, J. Gimeno, P. Martí-Aldaraví, Jhoan S. Giraldo; Methodology for Phase Doppler Anemometry Measurements on a Multi-Hole Diesel Injector. Experimental Techniques, 2016, 26, 889-919.

The $\mathrm{R}^{2}$ factor that correlates the theoretical profile with the measured mean velocities was $96.6 \%$. Consequently, the spray of interest was well aligned and presents a typical behavior.

\section{Conclusions}

In this work, a methodology for PDPA velocity measurements on multi-hole injectors has been presented, the following goals were overcome:

1. A geometrical characterization of the diesel injector was carried out. The opening angle was estimated with a standard deviation of $0.43^{\circ}$

2. The injector was successfully installed in the test rig and the manufactured parts. The device for spray isolation kept both emitter front and top windows clean and measurements were made without any issue.

3. A methodology of spray alignment was presented as well. MIE-Scattering technique was used to achieve this goal. Liquid contours were captured with a fast camera. Spray axis inclination was estimated by means of centroids which were calculated at each time step using the detected contours. The standard deviation of this calculation was $0.22^{\circ}$.

4. Preliminary PDPA velocity measurements were made, results were compared with theoretical approaches. It can be concluded that the spray isolation device was effective since the spray of interest had a typical behavior.

\section{Acknowledgment}

This research was performed in the frame of the project "Estudio de la interacción chorro-pared en condiciones realistas de motor" reference TRA2015-67679-c2-1-R from Ministerio de Economía y Competitividad (Spanish Ministry of Economy). The equipment used in this work has been partially supported by FEDER Project funds "Dotación de infraestructuras científico téctinas para el Centro Integral de Mejora Energética y Medioambiental de Sistemas de Transporte (CiMeT), (FEDERICTS-2012-06)", framed in the operation program of unique scientific and technical infrastructure of the Ministry of Science and Innovation of Spain. Jhoan S. Giraldo was supported by a research grant from Generalitat Valenciana (Programa Santiago Grisolia, GRISOLIA/2013/007). 
Raúl Payri, J. Gimeno, P. Martí-Aldaraví, Jhoan S. Giraldo; Methodology for Phase Doppler Anemometry Measurements on a Multi-Hole Diesel Injector. Experimental Techniques, 2016, 26, 889-919.

\section{Bibliography}

\section{References}

[1] Jeekuen Lee, Shinjae Kang, and Byungjoon Rho. Intermittent atomization characteristics of multi-hole and single-hole diesel nozzle. KSME International Journal, 16(12):1693-1701, 2002.

[2] B. H. Lee, J. H. Song, Y. J. Chang, and C. H. Jeon. Effect of the number of fuel injector holes on characteristics of combustion and emissions in a diesel engine. International Journal of Automotive Technology, 11(6):783-791, 2010.

[3] Jeekuen Lee, Shinjae Kaug, and Byungjoon Rho. Atomization characteristics of intermittent multi-hole diesel spray using time-resolved pdpa data. KSME International Journal, 17(5):766-775, 2003.

[4] L.-Y. Zhou, S.-F. Dong, H.-F. Cui, X.-W. Wu, F.-Y. Xue, and F.-Q. Luo. Measurements and analyses on the transient discharge coefficient of each nozzle hole of multi-hole diesel injector. Sensors and Actuators A: Physical, 244:198 - 205, 2016.

[5] Raul Payri, F.J. Salvador, Julien Manin, and Alberto Viera. Diesel ignition delay and lift-off length through different methodologies using a multi-hole injector. Applied Energy, 162:541 - 550, 2016.

[6] Raul Payri, Jose M. García-Oliver, Michele Bardi, and Julien Manin. Fuel temperature influence on diesel sprays in inert and reacting conditions. Applied Thermal Engineering, 35:185 - 195, 2012.

[7] F. Payri, Raul Payri, M. Bardi, and M. Carreres. Engine combustion network: Influence of the gas properties on the spray penetration and spreading angle. Experimental Thermal and Fluid Science, 53:236 - 243, 2014.

[8] Raul Payri, Jaime Gimeno, Michele Bardi, and Alejandro H. Plazas. Study liquid length penetration results obtained with a direct acting piezo electric injector. Applied Energy, 106(0):152 - 162, 2013.

[9] V. Soare. Phase Doppler Measurements in Diesel Dense Sprays: Optimisation of Measurements and Study of the Orifice Geometry Influence over the Spray at Microscopic Level. PhD thesis, Universitat Politècnica de Valencia, 2007.

[10] L. Araneo and C. Tropea. Improving phase doppler measurements in a diesel spray. SAE paper, 2000.

[11] A. Coghe and G.E. Cossali. Quantitative optical techniques for dense sprays investigation: A survey. Optics and Lasers in Engineering, 50(1):46 - 56, 2012. Advances in Flow Visualization. 
Raúl Payri, J. Gimeno, P. Martí-Aldaraví, Jhoan S. Giraldo; Methodology for Phase Doppler Anemometry Measurements on a Multi-Hole Diesel Injector. Experimental Techniques, 2016, 26, 889-919.

[12] Raul Payri, Lucio Araneo, Joseph Shakal, and Vlad Soare. Phase doppler measurements: system set-up optimization for characterization of a diesel nozzle. Journal of Mechanical Science and Technology, 22(8):1620-1632, 2008.

[13] J. M. Desantes, Raul Payri, F. J. Salvador, and V. Soare. Phase doppler measurements: system set-up optimization for characterization of a diesel nozzle. In $S A E$ Technical Paper. SAE International, 042005.

[14] Bracco F.V. Reitz R.D. On the dependence of spray angle and other spray parameters on nozzle design and operating conditions. SAE Technical Paper, 1979.

[15] M. Gavaises and A. Andriotis. Cavitation inside multi-hole injectors for large diesel engines and its effect on the near-nozzle spray structure. In SAE Technical Paper. SAE International, 042006.

[16] V. Macian, R. Payri, A. Garcia, and M. Bardi. Experimental evaluation of the best approach for diesel spray images segmentation. Experimental Techniques, 36(6):26$34,2012$.

[17] Raul Payri, Jaime Gimeno, Juan P. Viera, and Alejandro H. Plazas. Needle lift profile influence on the vapor phase penetration for a prototype diesel direct acting piezoelectric injector. Fuel, 113:257 - 265, 2013.

[18] Koo Ja-Ye Hung C. Calvin, Martin J.K. Injection pressure effects upon droplet behaviour in transient diesel sprays. SAE Paper, 1997.

[19] Jeekuen Lee, Shinjae Kang, and Byungjoon Rho. Time-resolved analysis of turbulent mixing flow characteristics of intermittent multi-hole diesel spray using 2-d pdpa. JSME International Journal Series B Fluids and Thermal Engineering, 46(3):425433, 2003.

[20] J. Sinnamon, D Lancaster, and J. Stiener. An experimental and analytical study of engine fuel spray trajectories. SAE Technical Paper, 1980.

[21] J. M. Desantes, F. J. Salvador, J. J. López, and J. De la Morena. Study of mass and momentum transfer in diesel sprays based on x-ray mass distribution measurements and on a theoretical derivation. Experiments in Fluids, 50(2):233-246, 2011.

[22] Hinze. Turbulence. McGraw-Hill. New York, 1975.

[23] H Schlichting. Boundary Layer Theory. McGraw-Hill, New York, 1979.

[24] J.M. Desantes, Raul Payri, F.J. Salvador, and A. Gil. Development and validation of a theoretical model for diesel spray penetration. Fuel, 85:910 - 917, 2006. 